\title{
Analytical method development and validation for simultaneous estimation of Teneligliptin hydrobromide hydrate and Metformin hydrochloride from it's pharmaceutical dosage form by three different UV spectrophotometric methods
}

\author{
Ashim Kumar Sen ${ }^{*}$, Denish N. Hinsu, Dhanya B. Sen, Aarti S. Zanwar, Rajesh A. Maheshwari, Vikas R. Chandrakar \\ Department of Pharmacy, Sumandeep Vidyapeeth University, Piparia, Waghodia, Vadodara-391760, Gujarat, India.
}

\begin{tabular}{|c|c|}
\hline ARTICLE INFO & ABSTRACT \\
\hline Article history: & \multirow{12}{*}{$\begin{array}{l}\text { Three new UV spectrophotometric methods namely simultaneous equation, absorbance ratio and first derivative } \\
\text { (zero crossing) spectroscopic methods were developed and validated for simultaneous estimation of teneligliptin } \\
\text { hydrobromide hydrate and metformin hydrochloride in tablet formulation which were simple, sensitive, precise } \\
\text { and accurate. In simultaneous equation method, absorbance was measured at } 237 \text { and } 246 \mathrm{~nm} \text { for both the drugs. } \\
\text { Teneligliptin hydrobromide hydrate and metformin hydrochloride was estimated using } 237 \text { and } 247.5 \mathrm{~nm} \text { in } \\
\text { absorbance ratio method. First derivative (zero crossing) method was based on the transformation of UV spectra } \\
\text { in to first derivative spectra followed by measurement of first derivative signal at } 237 \text { and } 246 \mathrm{~nm} \text { for } \\
\text { teneligliptin hydrobromide hydrate and metformin hydrochloride, respectively using } 2 \mathrm{~nm} \text { as wavelength } \\
\text { interval }(\Delta \lambda) \text { and } 1 \text { as scaling factor. Developed methods were validated according to ICH guidelines including } \\
\text { parameters viz., specificity, linearity and range, precision, accuracy, limit of detection and quantification. All the } \\
\text { three methods showed linear response in the concentration range of } 1-20 \mu \mathrm{g} / \mathrm{ml} \text { for both the drugs. Results of } \\
\text { method validation parameters follows ICH guideline acceptable limits. Based on the assay results obtained, } \\
\text { methods were compared using one-way ANOVA followed by Bonferroni multiple comparison tests ( } 95 \% \\
\text { confidence level) using computer based fitting program (Prism, Graphpad version 5, Graphpad Software Inc). } \\
\text { Outcome of the statistical analysis proved that there was no considerable dissimilarity between all the developed } \\
\text { methods. Methods were found to be simple, fast, highly sensitive, cost effective and hence can be useful for } \\
\text { simultaneous estimation of teneligliptin hydrobromide hydrate and metformin hydrochloride in commercial } \\
\text { tablet formulation for routine quality control analysis. }\end{array}$} \\
\hline Received on: $12 / 08 / 2016$ & \\
\hline 016 & \\
\hline Ac & \\
\hline Available online: $26 / 09 / 2016$ & \\
\hline Key words: & \\
\hline & \\
\hline hydrochloride, simultaneous & \\
\hline equation, absorbance ratio, & \\
\hline & \\
\hline methods, tablet formulation. & \\
\hline & \\
\hline
\end{tabular}

\section{INTRODUCTION}

Teneligliptin hydrobromide hydrate (TEN) is chemically described as $\{(2 \mathrm{~S}, 4 \mathrm{~S})-4-[4-(3-m e t h y l-1$ phenyl- $1 \mathrm{H}-$ pyrazol-5-yl) piperazin-1-yl] pyrrolidin-2-yl\} (1,3-thiazolidin-3yl) methanone hemipentahydrobromide hydrate is a dipeptidyl peptidase inhibitor. TEN slows the inactivation of incretin hormones, thereby increasing bloodstream concentrations and reducing fasting and postprandial glucose concentrations in a glucose-dependant manner in patients with type 2 diabetes

* Corresponding Author

Email: ashims01@gmail.com mellitus. The inhibition of DPP-4 increases the amount of active plasma incretins which helps with glycemic control (Yoshida et al., 2012; Kishimoto et al., 2013). Metformin hydrochloride (MET) is 1,1-dimethylbiguanide hydrochloride, a biguanide antidiabetic. It is given orally in the treatment of type 2 diabetes mellitus and is the drug of choice in overweight patients. They do not stimulate insulin release but require that some insulin be present in order to exert their antidiabetic effect. Possible mechanism of action includes the delay in the absorption of glucose from the GIT and increase in insulin sensitivity and glucose uptake in to cells and inhibition of hepatic gluconeogenesis (Indian Pharmacopoeia, 2007; The Merck Index, 2001; Martindale, 2009; Sen et al., 2015). 
For effective control of blood sugar in diabetic patients more than one medication is required. TEN shows effective control of blood sugar when combined with MET. Chemical structures of both the drugs are shown in Figure 1. Literature survey reveals various analytical methods for the estimation of TEN and MET individually using UV spectrophotometry (Shinde et al., 2016; Mubeen et al., 2009; Arayne et al., 2009), HPLC (Luhar et al., 2016; Chhetri et al., 2014; Umapathi et al., 2012), HPTLC (Shinde et al., 2016) and LC-MS/MS (Chunduri et al., 2016). Moreover, many methods were reported for the estimation of MET along with other drugs in combined formulation (Goswami et al., 2010; Mohamed et al., 2012; Satheeshkumar et al., 2014; Attimarad et al., 2014). However, the development of simultaneous estimation of TEN and MET in combined dosage form has not yet been reported by any method. Hence, this manuscript is the first to describe the development and validation of some simpler, sensitive, precise, accurate and cost effective UV spectroscopic methods for the simultaneous determination of TEN and MET in combined tablet formulation. Proposed methods possess several advantages which are as follows; methods describe very simple standard and sample preparation procedure, wide concentration range with high sensitivity and all the developed methods were validated as per ICH guidelines.

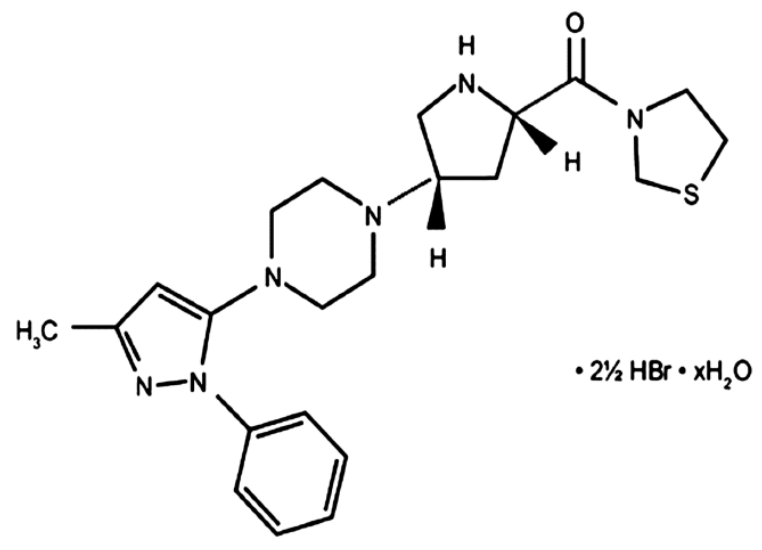

Teneligliptin hydrobromide hydrate<smiles>CN(C)C(=N)NC(=N)N</smiles>

\section{Metformin hydrochloride}

Fig. 1: Chemical structures of TEN (teneligliptin hydrobromide hydrate) and MET (metformin hydrochloride).

\section{MATERIALS AND METHODS}

\section{Chemicals and Reagents}

TEN reference standard used throughout the experiment was received as gift sample from Glenmark Pharmaceuticals Ltd.,
Mumbai, Maharashtra, India and MET was obtained from IPCA Laboratories, Mumbai, Maharashtra, India. The pharmaceutical formulation, Teniva $\mathbf{M}^{\circledR}$ tablet (Intas Pharmaceuticals Ltd., Ahmedabad, Gujarat, India) containing $20 \mathrm{mg}$ of TEN along with $500 \mathrm{mg}$ of MET was purchased from commercial sources. AR grade methanol was used as solvent and procured from Loba Chemie Pvt. Ltd., Mumbai, India.

\section{Apparatus}

Shimadzu double beam UV visible spectrophotometer (UV-1800, UV Probe, Shimadzu Corporation, Kyoto, Japan) with matched quartz cell of $1 \mathrm{~cm}$ path length was used throughout the experiment. Highly sensitive electronic balance Adventurer Pro AVG264C, Ohaus Corporation, Pine Brook, NJ, USA was used for weighing purpose.

\section{Preparation of Standard Solution}

Stock solution of TEN and MET were prepared individually by weighing accurately $10 \mathrm{mg}$ of standard drugs and transferred to a $10 \mathrm{ml}$ volumetric flask separately. Standard drugs were diluted to $10 \mathrm{ml}$ with methanol to get the concentration of the drugs $1000 \mu \mathrm{g} / \mathrm{ml}$. Further dilutions were made to get required concentration with methanol.

\section{Procedure}

\section{Simultaneous Equation and Absorbance Ratio Method}

Standard stock solutions containing $1000 \mu \mathrm{g} / \mathrm{ml}$ of TEN and MET were suitably diluted separately with methanol to obtain the drug solutions containing $8 \mu \mathrm{g} / \mathrm{ml}$. Both the solutions were scanned in the UV region (200 - $400 \mathrm{~nm}$ ) and spectra were recorded. Based on the spectral pattern, SE (simultaneous equation) and AR (absorbance ratio) methods [Beckett and Stenlake, 2005] were chosen for the estimation of both the drugs. From the overlain spectra (Figure 2), $237 \mathrm{~nm}\left(\lambda_{\max }\right.$ of MET) and $246 \mathrm{~nm}\left(\lambda_{\max }\right.$ of TEN) were selected for SE method. In case of AR method, $247.5 \mathrm{~nm}$ (isobestic point) and $237 \mathrm{~nm}\left(\lambda_{\max }\right.$ of MET) was selected, which showed excellent linearity and therefore used for simultaneous determination.

Varying concentrations ranging from $1-20 \mu \mathrm{g} / \mathrm{ml}$ of TEN and MET were prepared by diluting respective stock solutions. All the solutions were scanned in the UV region and absorbances were noted at 237 and $246 \mathrm{~nm}$ for SE; 237 and $247.5 \mathrm{~nm}$ for AR method. Absorptivity values were calculated for TEN and MET at their relevant wavelengths by applying following formula:

Absorptivity $=$ absorbance $/$ concentration $(\mathrm{gm} / 100 \mathrm{ml})$

Absorptivity value of individual solution at their respective wavelength was calculated and average absorptivity value (Table 1) at specific wavelength of particular drug was used for calculating concentration of drugs. 
Table 1: Average absorptivity values for SE and AR method.

\begin{tabular}{|c|c|c|c|c|c|c|c|}
\hline \multicolumn{4}{|c|}{ SE } & \multicolumn{4}{|c|}{$\mathbf{A R}$} \\
\hline \multicolumn{4}{|c|}{ Avg. absorptivity* } & \multicolumn{4}{|c|}{ Avg. absorptivity* } \\
\hline \multicolumn{2}{|c|}{ TENss } & \multicolumn{2}{|c|}{ MET } & \multicolumn{2}{|c|}{ TEN } & \multicolumn{2}{|c|}{ MET } \\
\hline $237 \mathrm{~nm}$ & $246 \mathrm{~nm}$ & $237 \mathrm{~nm}$ & $246 \mathrm{~nm}$ & $237 \mathrm{~nm}$ & $247.5 \mathrm{~nm}$ & $237 \mathrm{~nm}$ & $247.5 \mathrm{~nm}$ \\
\hline 274.28 & 315.41 & 593.94 & 380.41 & 274.28 & 312.39 & 593.94 & 312.39 \\
\hline
\end{tabular}

$*(n=6)$ Average of six determinations.

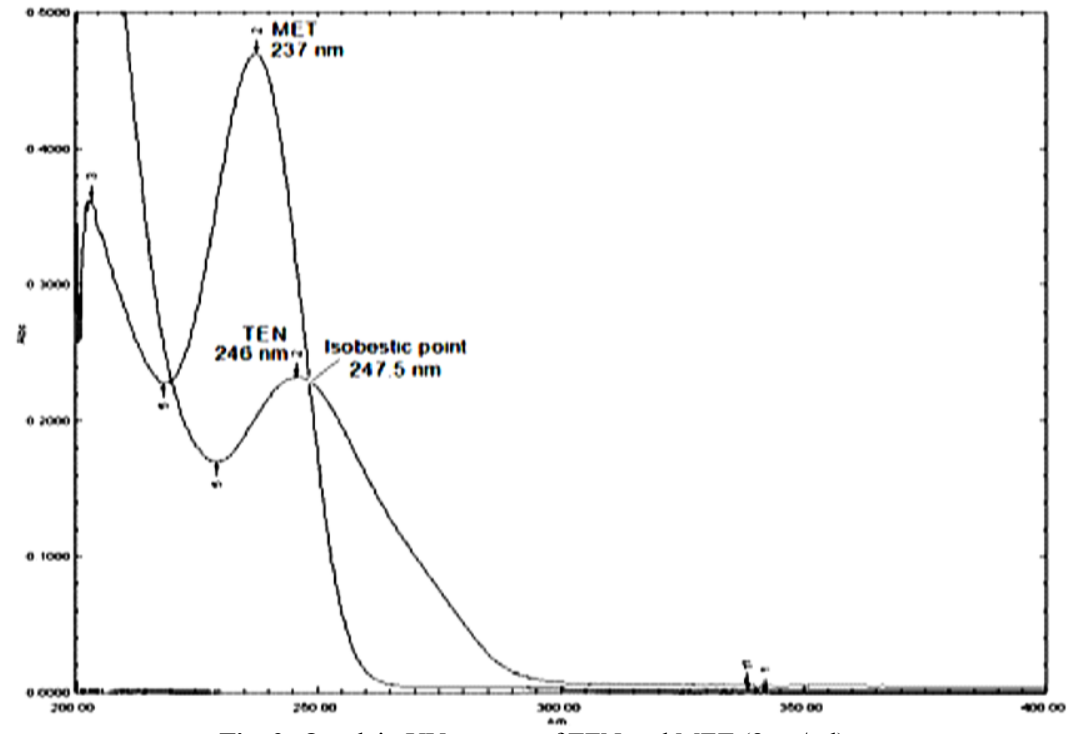

Fig. 2: Overlain UV spectra of TEN and MET $(8 \mu \mathrm{g} / \mathrm{ml})$

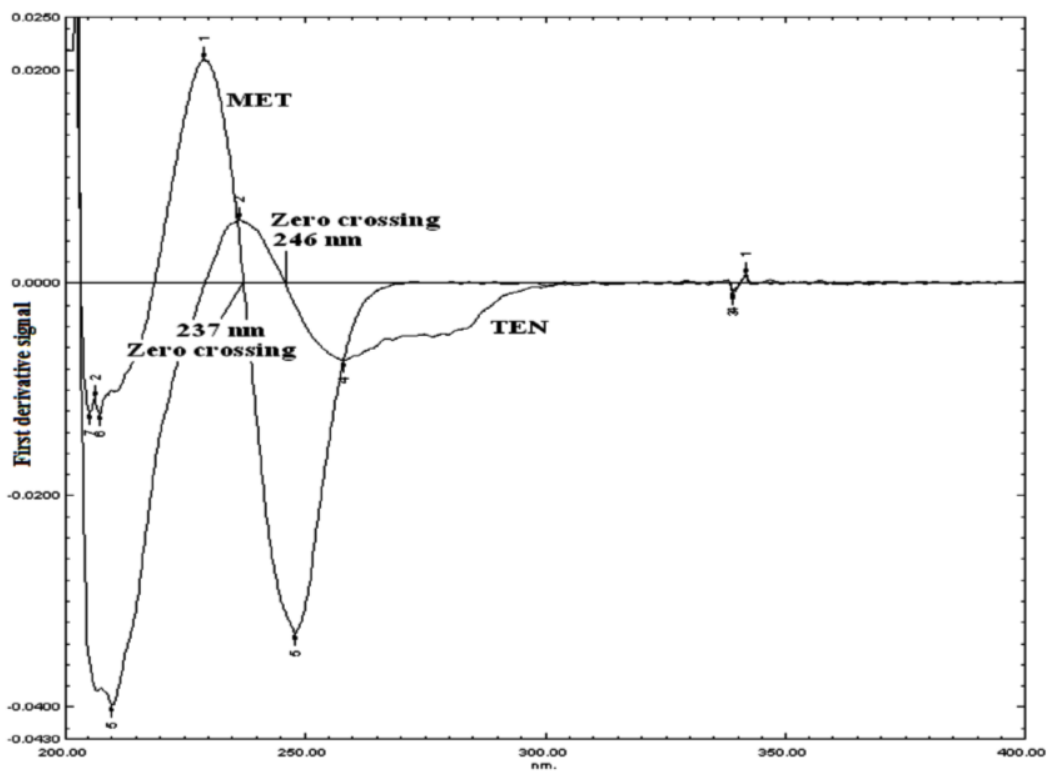

Fig. 3: Overlain $1^{\text {st }}$ derivative (zero crossing) UV spectra of TEN and MET $(8 \mu \mathrm{g} / \mathrm{ml})$.

\section{First Derivative (zero crossing) Method}

The normal UV spectra of TEN and MET were transformed into first and second derivative spectra. Based on the spectral pattern and zero crossing points, first DR (derivative spectroscopic) method was chosen for the study. First derivative spectra showed typical zero-crossing points at $246 \mathrm{~nm}$ for TEN and $237 \mathrm{~nm}$ for MET applying $2 \mathrm{~nm}$ as wavelength interval
$(\Delta \lambda)$ and 1 as scaling factor. After assessing overlain spectra, 237 $\mathrm{nm}$ and $246 \mathrm{~nm}$ were selected for further studies (Figure 3). Calibration curve was plotted for both TEN and MET in the concentration range of 1 to $20 \mu \mathrm{g} / \mathrm{ml}$.

Results were subjected to regression analysis by least square method to determine the values of slope, intercept and correlation coefficient. 


\section{Preparation of Sample Solution}

Twenty tablets of Teniva $\mathrm{M}^{\circledR}$ (Intas Pharmaceuticals Ltd., Ahmedabad, Gujarat, India) containing $20 \mathrm{mg}$ of TEN and $500 \mathrm{mg}$ of MET were accurately weighed and average weight was calculated. All the tablets were crushed to fine powder and quantity equivalent to $0.4 \mathrm{mg}$ of TEN and $10 \mathrm{mg}$ of MET were weighed and transferred to a previously cleaned and dried $50 \mathrm{ml}$ volumetric flask along with $9.6 \mathrm{mg}$ of standard TEN. After adding $30 \mathrm{ml}$ of methanol, flask was vortexed and shaken for 10 minutes and volume was made up to the mark using methanol. Flask contents were filtered using whatman filter paper no 41. Suitable aliquots were prepared and diluted to obtain required concentrations (eg. $10 \mu \mathrm{g} / \mathrm{ml}$ of TEN and MET).

\section{Analysis of Sample Solution \\ Simultaneous Equation Method}

After scanning the sample solution (formulation) between 200 to $400 \mathrm{~nm}$, responses were noted at 237 and $246 \mathrm{~nm}$. The unknown concentration of drugs present in the sample solution was estimated by solving following formula (Sen et al., 2016):

$$
\begin{gathered}
C x=\frac{A_{2} a_{y 1}-A_{1} a_{y 2}}{a_{x 2} a_{y 1}-a_{x 1} a_{y 2}} \\
C y=\frac{A_{1} a_{x 2}-A_{2} a_{x 1}}{a_{x 2} a_{y 1}-a_{x 1} a_{y 2}}
\end{gathered}
$$

Where $C x$ and $C y$ are the concentrations of TEN and MET, $a_{1}$ and $\mathrm{ax}_{2}$ are absorptivities of TEN at 237 and $246 \mathrm{~nm}$, respectively. ay ${ }_{1}$ and $\mathrm{ay}_{2}$ are absorptivities of MET at 237 and $246 \mathrm{~nm}$, respectively. $A_{1}$ and $A_{2}$ are the absorbances of sample solution at 237 and 246 $\mathrm{nm}$.

\section{Absorbance Ratio Method}

The unknown concentration of drugs in the sample solution was estimated by AR method applying following formula:

$$
\begin{aligned}
& \mathrm{Cx}=\frac{Q m-Q y}{Q \mathrm{x}-\mathrm{Qy}} \times \frac{\mathrm{A} 1}{a x 1} \\
& \mathrm{Cy}=\frac{Q m-Q x}{\mathrm{Qy}-\mathrm{Qx}} \times \frac{\mathrm{A} 1}{a y 1}
\end{aligned}
$$

Where, $\mathrm{ax}_{1}$ and $\mathrm{ax}_{2}$ are absorptivities of TEN at 237 and $247.5 \mathrm{~nm}$, respectively. ay $y_{1}$ and $\mathrm{ay}_{2}$ are absorptivities of MET at 237 and $247.5 \mathrm{~nm}$.

$\mathrm{A}_{1}$ and $\mathrm{A}_{2}$ are the absorbances of sample solution at 237 and $247.5 \mathrm{~nm}$. Cx and Cy are the concentrations of TEN and MET, respectively in sample solution.
$Q m=\frac{A 2}{A 1}$
$Q x=\frac{a x 2}{a \times 1}$
$Q y=\frac{a y 2}{a y 1}$

\section{First Derivative (zero crossing) Method}

Sample solution was scanned in the UV region (200-400 $\mathrm{nm}$ ) and spectrum was recorded and transformed into their $1^{\text {st }}$ derivative spectra and amplitude was measured at 237 or $246 \mathrm{~nm}$.
The unknown concentration of drugs present in the sample solution was estimated by using regression equation.

\section{Validation of Spectroscopic Methods}

The developed methods were validated in accordance with "International Conference on Harmonization" guidelines (ICH, 2005).

\section{Specificity}

To check the interference between tablet excipients used in the formulation and drug substance, specificity study was carried out. All the tablet excipients (as per marketed formulation) were mixed in proportion and diluted using methanol and filtered using whatman filter paper no 41. All the solutions (Placebo and standard) were scanned in the UV region and compared to assess the interference among excipients and drugs.

\section{Linearity and Range}

Linearity and range of all the three methods were checked by analyzing all the standard solutions separately, containing TEN and $\operatorname{MET}(1,4,8,12,16$ and $20 \mu \mathrm{g} / \mathrm{ml})$ in methanol and absorbances were noted at 237 and $246 \mathrm{~nm}$ for SE method; 237 and $247.5 \mathrm{~nm}$ for AR method; 237 and $246 \mathrm{~nm}$ for $1^{\text {st }}$ DR method. Calibration graphs were constructed using absorbances of standard drug solutions versus concentration in SE and AR method; $1^{\text {st }}$ derivative signal of standard drug solutions versus concentration in DR method. Regression analysis was performed by least squares method to determine the values of slope, intercept and correlation coefficient.

\section{Precision}

Precision of the methods were evaluated by performing repeatability, intra-day and inter-day precision studies. Repeatability of the methods were evaluated by analyzing sample solutions (TEN and MET: $4 \& 8 \mu \mathrm{g} / \mathrm{ml}$ ) six times by measuring the absorbances of both the drugs solution at 237 and $246 \mathrm{~nm}$ in SE method; 237 and $247.5 \mathrm{~nm}$ for AR method; 237 and $246 \mathrm{~nm}$ for $1^{\text {st }}$ DR method, respectively and \% RSD was calculated. Intra-day precision was performed by analyzing sample solutions (TEN and MET: $4 \& 8 \mu \mathrm{g} / \mathrm{ml}$ ) in triplicate at two different concentration levels for three times on the same day within the linearity range and \% RSD was calculated. Inter-day precision was evaluated by repeated analysis of sample solutions (TEN and MET: 4 \& 8 $\mu \mathrm{g} / \mathrm{ml}$ ) in triplicate at two different concentration levels within the linearity range on three different days and percentage RSD was calculated.

\section{Accuracy}

In order to ensure the suitability and reliability of the projected methods, recovery studies were performed by standard addition method. To an equivalent quantity of pre-analyzed sample solution (TEN and MET: 4, $8 \& 12 \mu \mathrm{g} / \mathrm{ml}$ ), a known concentration of standard TEN and MET were added at 50, 100 and $150 \%$ level and the resulting solutions were reanalyzed by projected methods 
and $\%$ recoveries were calculated. The outcome of accuracy studies were assessed based on the percentage of standard TEN and MET recovered from the formulation by applying following formula:-

$\%$ Recovery

$=$ (Amount of drug found after addition of standard drug

- Amount of drug found before addition of standard drug)

/(Amount of standard drug added $) \times 100$

\section{$L O D$ and $L O Q$}

Sensitivity of the proposed methods were determined in terms of LOD and LOQ. The limit of detection and limit of quantification of TEN and MET were calculated applying following equation as per ICH guidelines.

$$
\begin{aligned}
& L O D=3.3 \times \frac{\sigma}{S} \\
& L O Q=10 \times \frac{\sigma}{S}
\end{aligned}
$$

Where $\sigma=$ The standard deviation of the response, $S=$ The slope of the calibration curve

\section{Stability of the Solution}

Stability of the solutions were checked by observing any changes in terms of absorbance and spectral pattern which was compared to freshly prepared solutions by keeping the solutions at room temperature and analyzing at frequent intervals.

\section{RESULTS AND DISCUSSION}

Three UV spectroscopic methods namely SE, AR and $1^{\text {st }}$ DR spectroscopic methods were developed and validated for simultaneous estimation of TEN and MET in tablet dosage form which are simple, sensitive, precise and accurate. In SE method, absorbance was measured at 237 and $246 \mathrm{~nm}$ for both the drugs. In AR method 237 and $247.5 \mathrm{~nm}$ was used for the detection and quantification of TEN and MET. $1^{\text {st }}$ DR method was based on the transformation of UV-spectra in to first derivative spectra and followed by measurement of first derivative signal at 237 and 246 $\mathrm{nm}$ for TEN and MET, respectively using $2 \mathrm{~nm}$ as wavelength interval $(\Delta \lambda)$ and 1 as scaling factor. Comparative overlain spectra of placebo and drug solutions indicate that there was no interference between excipients and standard drugs (Figure $4 \& 5$ ). Linear relation was established for TEN and MET in the concentration range of $1-20 \mu \mathrm{g} / \mathrm{ml}$ for all the methods. Overlain spectra of TEN and MET are shown in Figure $6 \&$ 7. Calibration graphs were plotted using absorbance of standard drug solution versus concentration for SE and AR method. $1^{\text {st }}$ derivative signal of standard drug solution versus concentration was used to plot calibration curve for $1^{\text {st }}$ DR method. Regression analysis was performed by applying least square method for calculating values of slope, intercept and correlation coefficient for TEN and MET at their relative wavelengths. Outcome of precision studies were evaluated in terms of \% RSD, follows ICH guideline acceptable limits $(<2)$, which shows good repeatability, low intra and interday variability, indicating an excellent precision of the developed methods (Table 2). The outcome of recovery studies ranged from 97-102\% for both the drug suggests suitability of the proposed methods (Table 3). Percentage recovery indicates that there was no interference from tablet excipients. Moreover, low LOD and LOQ values prove the sensitivity of the proposed methods (Table 2). Solution stability was checked at room temperature and it was found to be stable up to two days. The projected methods were successfully applied for the quantitative determination of TEN and MET in tablet formulation (Teniva $\mathrm{M}^{\circledR}$ tablet: $20 \mathrm{mg}$ of TEN and $500 \mathrm{mg}$ of MET). Sample solutions were analyzed six times and experimental values were found to be within 96 and $100 \%$ for both the drugs and hence the developed methods can be used for the simultaneous determination of both the drugs in combined tablet formulation (Table 4).

Statistical analysis was performed to check the effect of all three developed methods based on assay results obtained. Statistical significance between all the three methods were tested using one-way ANOVA followed by Bonferroni multiple comparison test (95\% confidence level) using computer based fitting program (Prism, Graphpad version 5, Graphpad software Inc). Significance level was set at $\mathrm{p}<0.05$ for all the tests. Results of ANOVA are presented in Table 5. The results of assay proved that there was no considerable dissimilarity between all the developed methods.

\begin{tabular}{|c|c|c|c|c|c|c|c|c|c|c|}
\hline \multirow{3}{*}{$\begin{array}{l}\text { Parameters } \\
\text { Wavelengths (nm) }\end{array}$} & \multicolumn{4}{|c|}{ SE } & \multicolumn{4}{|c|}{$\mathbf{A R}$} & \multicolumn{2}{|c|}{ DR } \\
\hline & \multicolumn{2}{|c|}{ TEN } & \multicolumn{2}{|c|}{ MET } & \multicolumn{2}{|c|}{ TEN } & \multicolumn{2}{|c|}{ MET } & \multirow{2}{*}{$\begin{array}{c}\text { TEN } \\
237\end{array}$} & \multirow{2}{*}{$\begin{array}{c}\text { MET } \\
246\end{array}$} \\
\hline & 237 & 246 & 237 & 246 & 237 & 247.5 & 237 & 247.5 & & \\
\hline Linearity range $(\mu \mathrm{g} / \mathrm{ml})$ & \multicolumn{10}{|c|}{$1-20$} \\
\hline Correlation coefficient & 0.9996 & 0.9984 & 0.9993 & 0.9993 & 0.9984 & 0.9984 & 0.9993 & 0.9984 & 0.9987 & 0.9995 \\
\hline \multicolumn{11}{|l|}{ Regression equation } \\
\hline Slope & 0.0259 & 0.0304 & 0.0576 & 0.0365 & 0.0258 & 0.0303 & 0.0576 & 0.0303 & 0.0008 & 0.0039 \\
\hline Intercept & 0.0079 & 0.0011 & 0.0104 & 0.0084 & 0.0035 & 0.0003 & 0.0104 & 0.0003 & 0.0005 & 0.0001 \\
\hline LOD $(\mu \mathrm{g} / \mathrm{ml})$ & 0.16 & 0.29 & 0.05 & 0.18 & 0.16 & 0.24 & 0.05 & 0.24 & 0.18 & 0.06 \\
\hline LOQ $(\mu \mathrm{g} / \mathrm{ml})$ & 0.49 & 0.89 & 0.15 & 0.55 & 0.49 & 0.74 & 0.15 & 0.74 & 0.51 & 0.19 \\
\hline Specificity & \multicolumn{10}{|c|}{ No interferences } \\
\hline $\begin{array}{l}\text { Precision (\% RSD) Repeatability of } \\
\text { measurement }(n=6) *\end{array}$ & 0.52 & 0.81 & 0.83 & 0.38 & 0.92 & 0.84 & 0.52 & 0.86 & 1.11 & 1.16 \\
\hline Intra-day $(n=3)^{*}$ & 0.61 & 0.65 & 0.68 & 0.64 & 0.87 & 0.65 & 0.84 & 0.28 & 0.89 & 0.63 \\
\hline Inter-day $(n=3)^{*}$ & 0.87 & 1.05 & 0.29 & 1.02 & 0.61 & 0.93 & 0.71 & 0.62 & 0.73 & 0.84 \\
\hline
\end{tabular}

Table 2: Summary of linear regression and method validation data for the proposed methods.

$*_{\mathrm{n}}=$ number of determinations, \% RSD (Percentage relative standard deviation). 
Table 3: Recovery data of the proposed methods.

\begin{tabular}{|c|c|c|c|c|c|c|c|}
\hline \multirow{2}{*}{ Drugs } & \multirow[b]{2}{*}{ Level (\%) } & \multicolumn{3}{|c|}{ Recovery $(\%) *$} & \multicolumn{3}{|c|}{ RSD (\%) } \\
\hline & & SE & $\mathbf{A R}$ & DR & SE & $\mathbf{A R}$ & DR \\
\hline \multirow{3}{*}{ TEN } & 50 & $98.14 \pm 0.81$ & $98.25 \pm 0.34$ & $99.84 \pm 0.49$ & 0.82 & 0.34 & 0.49 \\
\hline & 100 & $101.01 \pm 0.38$ & $99.29 \pm 0.61$ & $98.93 \pm 0.72$ & 0.38 & 0.61 & 0.73 \\
\hline & 150 & $98.19 \pm 0.52$ & $98.81 \pm 0.34$ & $98.41 \pm 1.08$ & 0.52 & 0.34 & 1.09 \\
\hline \multirow{3}{*}{ MET } & 50 & $98.49 \pm 0.63$ & $97.93 \pm 0.73$ & $100.12 \pm 0.82$ & 0.64 & 0.74 & 0.83 \\
\hline & 100 & $97.81 \pm 0.16$ & $98.86 \pm 1.03$ & $100.26 \pm 0.46$ & 0.16 & 1.04 & 0.46 \\
\hline & 150 & $98.28 \pm 0.35$ & $99.59 \pm 0.67$ & $99.37 \pm 0.96$ & 0.35 & 0.67 & 0.97 \\
\hline
\end{tabular}

*Mean \pm SD $(\mathrm{n}=3)$, SD (Standard deviation), \% RSD (Percentage relative standard deviation).

Table 4: Results of formulation analysis using different methods.

\begin{tabular}{|c|c|c|c|c|c|c|c|c|c|c|}
\hline \multirow{2}{*}{ Drugs } & \multirow{2}{*}{$\begin{array}{c}\text { Labeled Amount } \\
\text { (mg/tab) }\end{array}$} & \multicolumn{3}{|c|}{ Amount Found (mg/tab) } & \multicolumn{3}{|c|}{ Amount Found (\%)* } & \multicolumn{3}{|c|}{ RSD (\%) } \\
\hline & & SE & $\mathbf{A R}$ & DR & SE & $\mathbf{A R}$ & DR & SE & $\mathbf{A R}$ & DR \\
\hline TEN & 20 & 19.75 & 19.61 & 19.52 & $98.75 \pm 0.48$ & $98.05 \pm 0.45$ & $97.60 \pm 0.81$ & 0.50 & 0.47 & 0.83 \\
\hline MET & 500 & 494.80 & 496.23 & 491.57 & $98.96 \pm 0.93$ & $99.25 \pm 0.72$ & $98.31 \pm 1.02$ & 0.95 & 0.74 & 1.05 \\
\hline
\end{tabular}

*Mean \pm SD $(\mathrm{n}=6), \mathrm{SD}$ (Standard deviation), \% RSD (Percentage relative standard deviation).

Table 5: Results of statistical comparison using one way ANOVA \& Bonferroni multiple comparison tests for SE, AR and DR spectroscopic methods.

\begin{tabular}{|c|c|c|c|}
\hline Drugs & Simultaneous Equation Method & Absorbance Ratio Method & First Derivative Method \\
\hline TEN & $98.75 \pm 0.48$ & $98.05 \pm 0.45$ & $97.60 \pm 0.81$ \\
\hline MET & $98.96 \pm 0.93$ & $99.25 \pm 0.72$ & $98.31 \pm 1.02$ \\
\hline
\end{tabular}

All values are expressed in Mean \pm SD $(n=6)$.

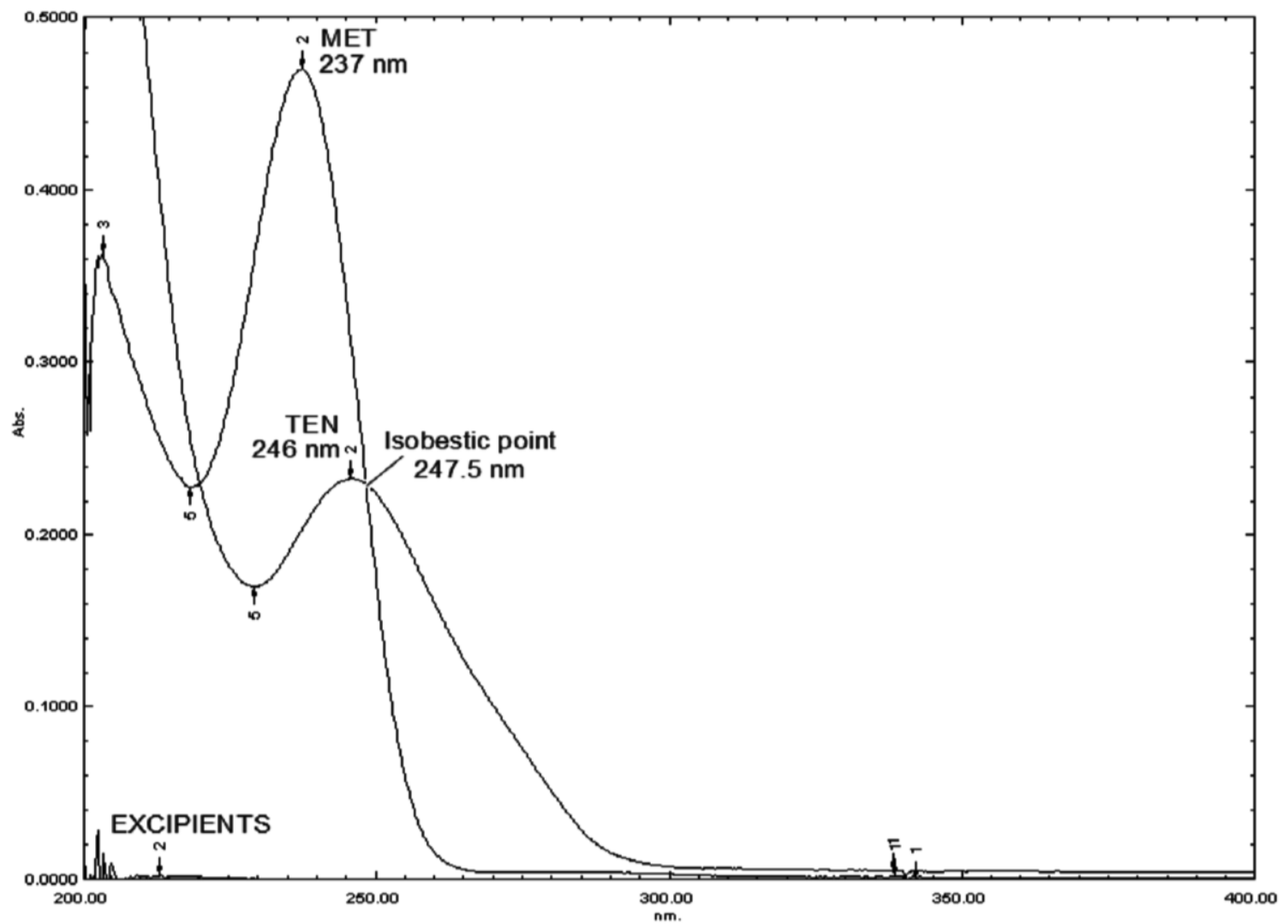

Fig. 4: Overlain UV spectra of formulation excipients and standard drugs for SE and AR methods. 


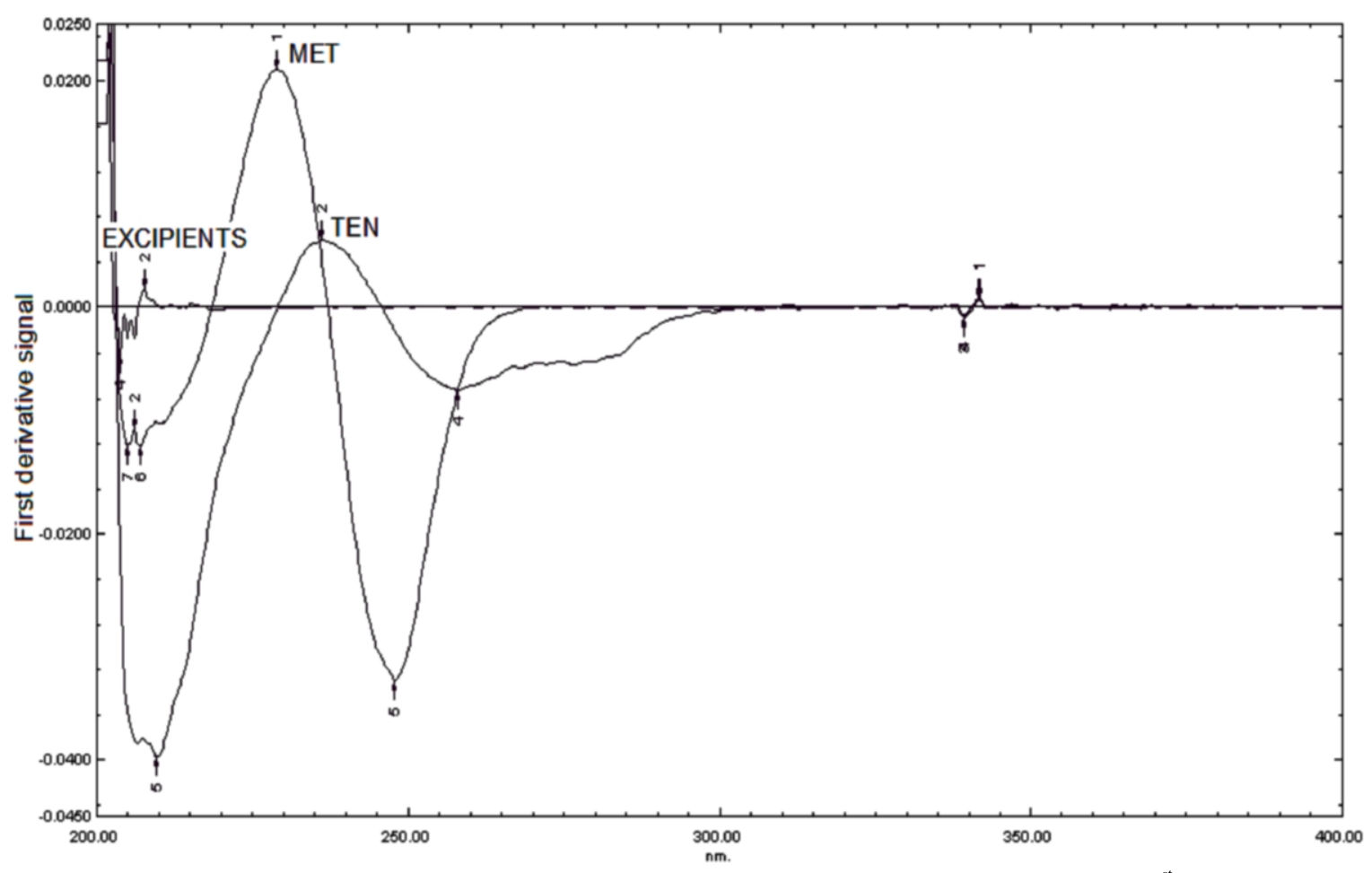

Fig. 5: Overlain first derivative (zero crossing) UV spectra of formulation excipients and standard drugs for $1^{\text {st }}$ DR method.

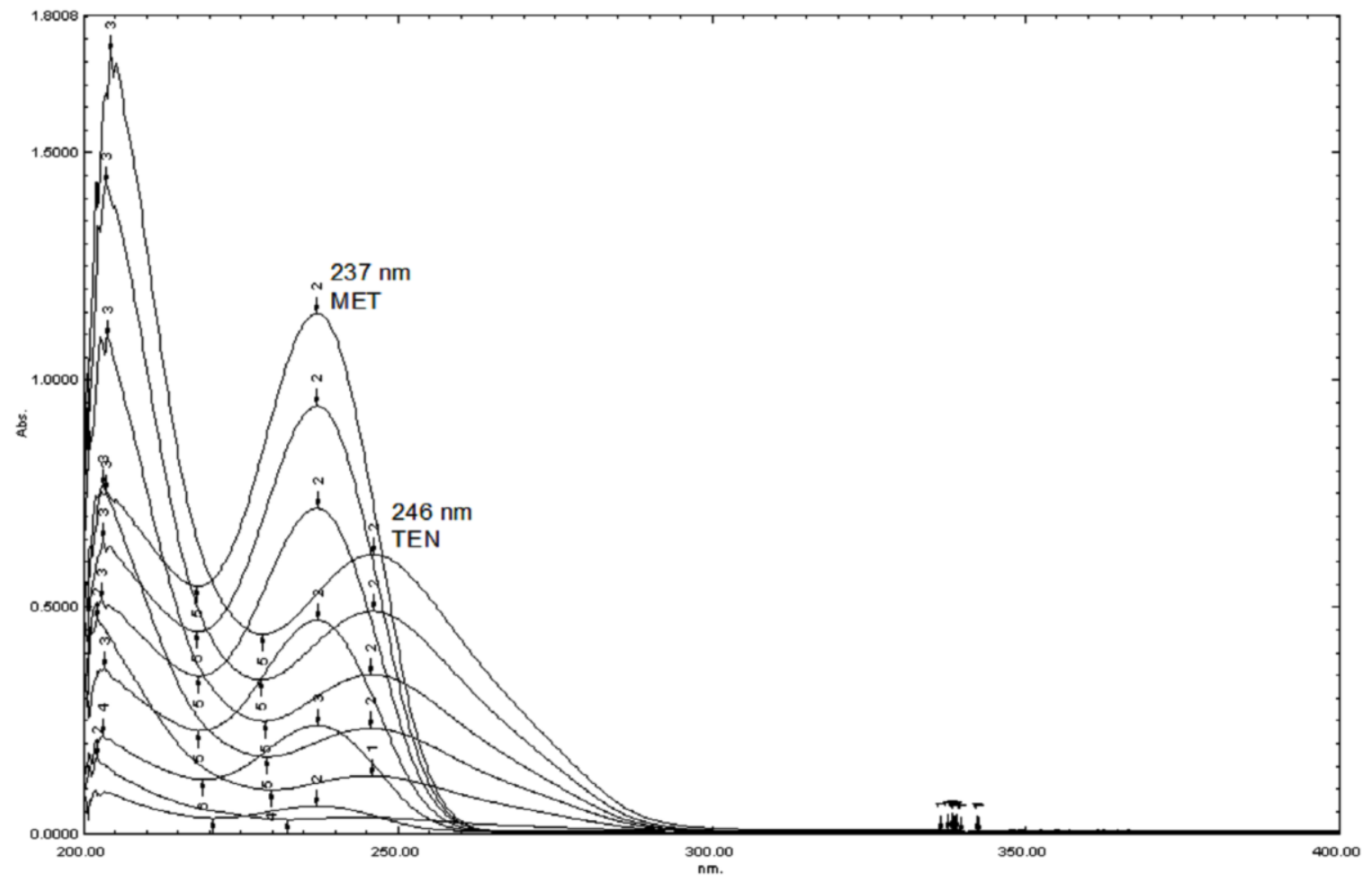

Fig. 6: Overlain UV spectra of TEN and MET (1-20 $\mu \mathrm{g} / \mathrm{ml})$ for SE and AR methods. 


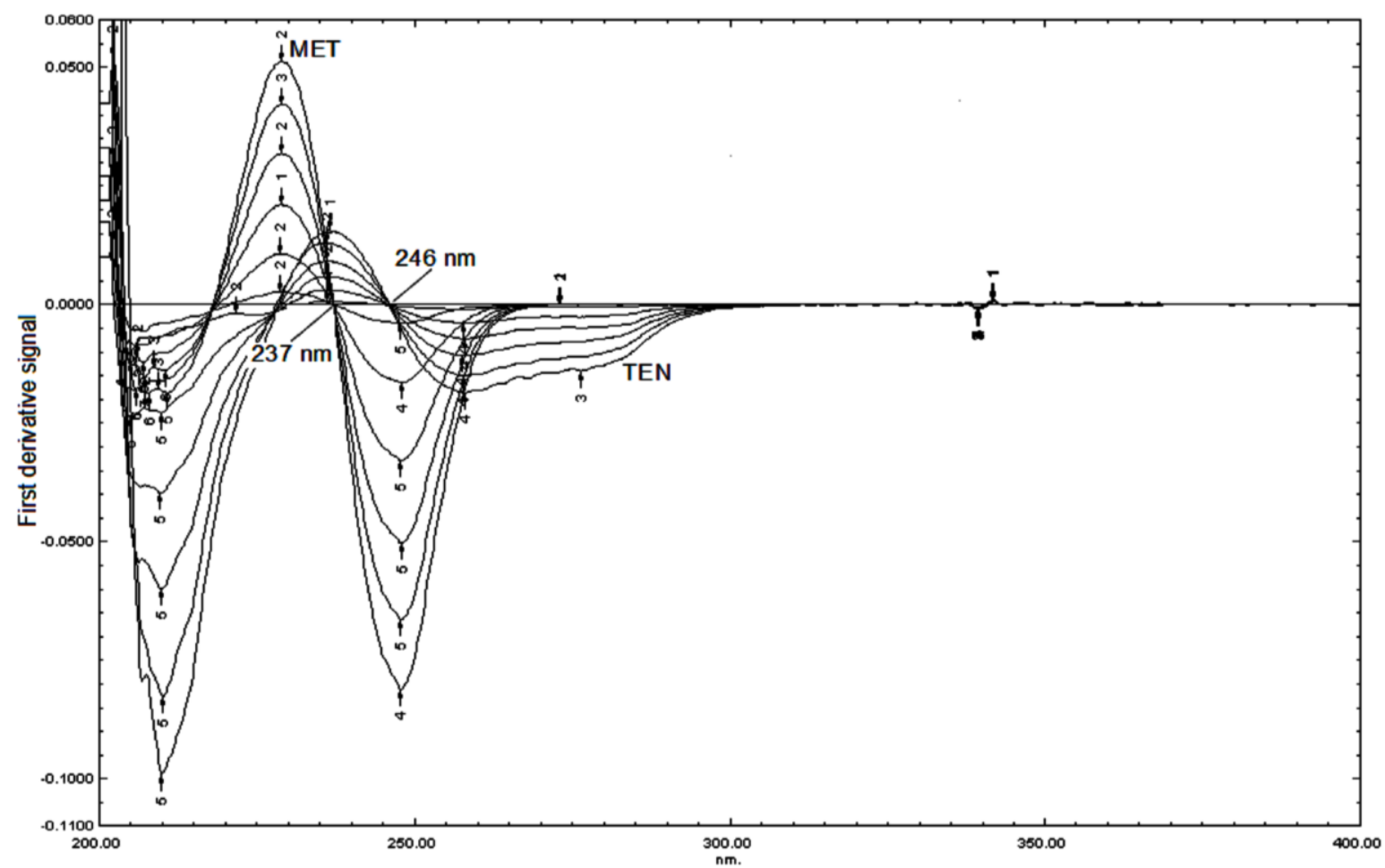

Fig. 7: Overlain $1^{\text {st }}$ derivative (zero crossing) UV spectra of TEN and MET (1-20 $\left.\mu \mathrm{g} / \mathrm{ml}\right)$ for $1^{\text {st }}$ DR method.

\section{CONCLUSION}

Three different methods namely SE, AR and $1^{\text {st }}$ DR spectroscopic methods were developed for simultaneous estimation of TEN \& MET in combined tablet dosage form. Developed methods were validated according to $\mathrm{ICH}$ guidelines. Projected methods were found to be simple, sensitive, precise, accurate and cost effective. Moreover, all the developed UVspectrophotometric methods require little sample preparation procedure and have wide concentration range with high sensitivity. Statistical data reveals that there is no statistical significant dissimilarity among all the three methods. Therefore, all the developed methods can be used successfully for routine quality control analysis of TEN and MET in combined tablet dosage form.

\section{ACKNOWLEDGEMENT}

Authors are thankful to the Department of Pharmacy, Sumandeep Vidyapeeth University, Piparia, Waghodia, Vadodara, Gujarat, India for providing all the facilities throughout the work.

\section{Financial support and sponsorship: Nil.}

Conflict of Interests: There are no conflicts of interest.

\section{REFERENCES}

Yoshida T, Akahoshi F, Sakashita H, Kitajima H, Nakamura M, Sonda S. et al. Discovery and preclinical profile of teneligliptin (3- [(2S,4S)-4- [4- (3- methyl-1- phenyl- 1H -pyrazol-5-yl) piperazin -1- yl]pyrrolidin-2-ylcarbonyl]thiazolidine): A highly potent, selective, longlasting and orally active dipeptidyl peptidase IV inhibitor for the treatment of type 2 diabetes. Bioorganic \& Medicinal Chemistry, 2012;20(19):570519.

Kishimoto M. Teneligliptin: A DPP-4 inhibitor for the treatment of type 2 diabetes. Diabetes, Metabolic Syndrome and Obesity: Targets and Therapy, 2013;6:187-95.

Indian Pharmacopoeia, Government of India, Ministry of Health \& Family Welfare, Volume-2, Ghaziabad, The Indian Pharmacopoeia Commission, 2007;1358-59.

The Merck Index, Merck \& Co Inc, White House Station, New Jersey, USA, $13^{\text {th }}$ Edition, 2001,1061.

Martindale, The complete drug reference. $36^{\text {th }}$ Edition. Vol. I. London (UK): Pharmaceutical Press (An Imprint of RPS Publishing); 2009. 453-54.

Sen DB, Sen AK, Zanwar AS, Balaraman R, Seth AK. Determination of alogliptin benzoate and metformin hydrochloride in tablet dosage form by simultaneous equation and absorption ratio method. International Journal of Pharmacy and Pharmaceutical Sciences, 2015;7(8):380-83

Shinde VC, Aher KB, Bhavar GB, Kakad SJ, Chaudhari SR. Development and validation of UV spectrophotometric method and high performance thin layer chromatographic (HPTLC) method for estimation of teneligliptin hydrobromide in pharmaceutical preparation. Der Pharmacia Lettre, 2016;8(8):291-301.

Mubeen G, Noor K. Spectrophotometric method for analysis of metformin hydrochloride. Indian Journal of Pharmaceutical Sciences, 2009;71(1):100-02.

Arayne MS, Sultana N, Zuberi MH, Siddiqui FA. Spectrophotometric quantitation of metformin in bulk drug and pharmaceutical formulations using multivariate technique. Indian Journal of Pharmaceutical Sciences, 2009;71(3):331-35.

Luhar SV, Pandya KR, Jani GK, Narkhed SB. Simultaneous estimation of teneligliptin hydrobromide hydrate and its degradation product by RP-HPLC method. Journal of Pharmaceutical Sciences and Bioscientific Research, 2016;6(3):254-61. 
Chhetri HP, Thapa P, Schepdael AV. Simple HPLC-UV method for the quantification of metformin in human plasma with one step protein precipitation. Soudi Pharmaceutical Journal, 2014;22(5):483-87.

Umapathi P, Ayyappan J, Quine SD. Quantitative determination of metformin hydrochloride in tablet formulation containing croscarmellose sodium as disintegrant by HPLC and UV spectrophotometry. Tropical Journal of Pharmaceutical Research, 2012;11(1):107-16.

Chunduri RHB, Dannana GS. Development and validation of LC-MS/MS method for quantification of teneligliptin in human plasma and its application to a pharmacokinetic study. World Journal of Pharmacy and Pharmaceutical Sciences, 2016;5(5):833-50.

Goswami L, Mukhopadhyay S, Durgapal S. Simultaneous estimation of metformin and pioglitazone by ultraviolet spectrophotometry. Indian Journal of Pharmaceutical Sciences, 2010;72(4):508 10.

Mohamed S, Nahed E, Fathallah B, Mohamed W, Gabor P. Simultaneous determination of sitagliptin and metformin in pharmaceutical preparations by capillary zone electrophoresis and its application to human plasma analysis. Analytical Chemistry Insights, 2012;7:31-46.

Satheeshkumar N, Pradeepkumar M, Shanthikumar S, Rao VJ. Development of validated stability indicating assay method for simultaneous estimation of metformin hydrochloride and vildagliptin by RP-HPLC. Drug Research (Stuttg), 2014;64(3):124-29.

Attimarad M, Nagaraja SH, Aldhubaib BE, Nair A, Venugopala KN. Simultaneous determination of metformin and three gliptins in pharmaceutical formulations using RP-HPLC: application to stability studies on linagliptin tablet formulation. Indian Journal of Pharmaceutical Education and Research, 2014;48(4):45-53.
Beckett AH, Stenlake JB. Instrumental methods in the development and use of medicines. In, Practical pharmaceutical chemistry (Part-2), $4^{\text {th }}$ edition. New Delhi, CBS Publishers and Distributors, 2005;13,275-99.

Sen AK, Sen DB, Maheshwari RA, Balaraman R, Seth AK. Simultaneous estimation of aliskiren hemifumarate and hydrochlorothiazide in combined tablet formulation by simultaneous equation, absorbance ratio and first derivative spectroscopic methods. Journal of Applied Pharmaceutical Science, 2016;6(7):164-70.

International Conference on Harmonization (ICH). Validation of Analytical Procedures: Text and Methodology Q2(R1). Geneva; 2005.

\section{How to cite this article:}

Sen AK, Hinsu DN, Sen DB, Zanwar AS, Maheshwari RA, Chandrakar VR. Analytical method development and validation for simultaneous estimation of Teneligliptin hydrobromide hydrate and Metformin hydrochloride from its pharmaceutical dosage form by three different UV spectrophotometric methods. J App Pharm Sci, 2016; 6 (09): 157-165. 